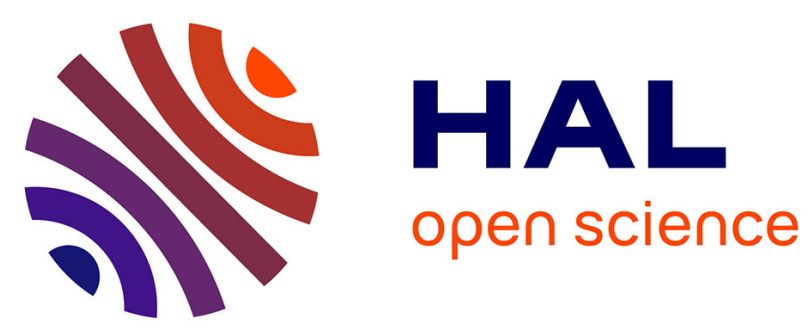

\title{
Solar quiet current response in the African sector due to a 2009 sudden stratospheric warming event
}

\author{
O. S. Bolaji, E. O. Oyeyemi, O. P. Owolabi, Y. Yamazaki, A. B. Rabiu, D.
}

Okoh, A. Fujimoto, Christine Amory-Mazaudier, G. K. Seemala, A.

Yoshikawa, et al.

\section{To cite this version:}

O. S. Bolaji, E. O. Oyeyemi, O. P. Owolabi, Y. Yamazaki, A. B. Rabiu, et al.. Solar quiet current response in the African sector due to a 2009 sudden stratospheric warming event. Journal of Geophysical Research Space Physics, 2016, 10.1002/2016JA022857 . hal-01358396

\section{HAL Id: hal-01358396 \\ https://hal.sorbonne-universite.fr/hal-01358396}

Submitted on 31 Aug 2016

HAL is a multi-disciplinary open access archive for the deposit and dissemination of scientific research documents, whether they are published or not. The documents may come from teaching and research institutions in France or abroad, or from public or private research centers.
L'archive ouverte pluridisciplinaire HAL, est destinée au dépôt et à la diffusion de documents scientifiques de niveau recherche, publiés ou non, émanant des établissements d'enseignement et de recherche français ou étrangers, des laboratoires publics ou privés. 


\section{Journal of Geophysical Research: Space Physics}

\section{RESEARCH ARTICLE \\ 10.1002/2016JA022857 \\ Solar quiet current response in the African sector due to a 2009 sudden stratospheric warming event}

Key Points:

- The closer a station to the dip equator, the more intense the S_qH magnitude when there is no SSW

- Their is possibility of reinjection of energy in the jet as its flows eastward

- Reduction of upward propagating tides from the middle atmosphere

Correspondence to:

O. S. Bolaji,

oloriebimpjch2002@yahoo.co.uk

\section{Citation:}

Bolaji, O. S., et al. (2016), Solar quiet current response in the African sector due to a 2009 sudden stratospheric warming event, J. Geophys. Res. Space Physics, 121, doi:10.1002/2016JA022857.

Received 14 MAY 2016 Accepted 4 AUG 2016 Accepted article online 6 AUG 2016

○2016. American Geophysical Union. All Rights Reserved.

\author{
O. S. Bolaji ${ }^{1,2}$, E. O. Oyeyemi' ', O. P. Owolabi', Y. Yamazaki ${ }^{3}$, A. B. Rabiu ${ }^{4}$, D. Okoh ${ }^{4}$, A. Fujimoto ${ }^{5}$, \\ C. Amory-Mazaudier ${ }^{6,7}$, G. K. Seemala ${ }^{8}$, A. Yoshikawa ${ }^{5}$, and O. K. Onanuga ${ }^{9}$ \\ ${ }^{1}$ Department of Physics, University of Lagos, Lagos, Nigeria, ${ }^{2}$ Department of Physics, University of Tasmania, Australia, \\ ${ }^{3}$ Department of Physics, Lancaster University, Lancaster, UK, ${ }^{4}$ Center for Atmospheric Research and National Space Research \\ and Development Agency, Kogi State University Campus, Anyigba, Nigeria, ${ }^{5}$ International Centre for Space Weather Science \\ and Education, Kyushu University, Fukuoka, Japan, ${ }^{6}$ Sorbonne Paris, UPMC University Paris VI, LPP, Paris, France, ${ }^{7} \mathrm{~T} / \mathrm{ICT} 4 \mathrm{D}$, \\ Abdus Salam International Centre for Theoretical Physics, Trieste, Italy, ${ }^{8}$ Indian Institute of Geomagnetism, Navi Mumbai, India, \\ ${ }^{9}$ Department of Science Laboratory Technology, Lagos State Polytechnics, Lagos, Nigeria
}

Abstract We present solar quiet $\left(S_{q}\right)$ variation of the horizontal $(H)$ magnetic field intensity deduced from Magnetic Data Acquisition System (MAGDAS) records over Africa during an unusual strong and prolonged 2009 sudden stratospheric warming (SSW) event. A reduction in the $S_{q} H$ magnitude that enveloped the geomagnetic latitudes between $21.13^{\circ} \mathrm{N}$ (Fayum FYM) in Egypt and $39.51^{\circ} \mathrm{S}$ (Durban DRB) in South Africa was observed, while the stratospheric polar temperature was increasing and got strengthened when the stratospheric temperature reached its maximum. Another novel feature associated with the hemispheric reduction is the reversal in the north-south asymmetry of the $S_{q} H$, which is indicative of higher $S_{q} H$ magnitude in the Northern Hemisphere compared to the Southern Hemisphere during SSW peak phase. The reversal of the equatorial electrojet (EEJ) or the counter electrojet (CEJ) was observed after the polar stratospheric temperature reached its maximum. The effect of additional currents associated with CEJ was observed in the Southern Hemisphere at middle latitude. Similar changes were observed in the EEJ at the South America, Pacific Ocean, and Central Asia sectors. The effect of the SSW is largest in the South American sector and smallest in the Central Asian sector.

\section{Introduction}

A space weather event sometimes causes a severe disturbance of the upper atmosphere and the near-Earth space environment driven by the magnetic activity of the Sun, which subsequently influences the variability of the Earth's ionosphere. The solar quiet $\left(S_{q}\right)$ current system is a well-known phenomenon found in the $E$ region of the ionosphere (approximately $90-150 \mathrm{~km}$ in altitude). It produces a regular daily ground magnetic variations during geomagnetically quiet days on the Earth's surface, and their strength changes on various time scales [Onwumechili, 1967]. This current is due to the electric currents in the ionized upper atmosphere, where their impulsion is attributed to electromotive forces caused by neutral winds, mainly horizontal, in the presence of the geomagnetic field [Richmond and Roble, 1987]. The orthogonality of the electric and magnetic fields over the dip equator generates large eastward conductivities in the daytime and an enhanced eastward current; equatorial electrojet (EEJ) is initiated [Baker and Martyn, 1953]. The daytime reversal of the EEJ current during geomagnetically quiet periods is described by Gouin and Mayaud [1967] as counter electrojet (CEJ).

Shiokawa et al. [2009] reported that gravity, tidal, and planetary waves, which are usually generated in the lower atmosphere could propagate into the upper atmosphere under favorable background conditions and couple to the ionosphere. They found that a substantial fraction of observed variability in the ionosphere could be associated with meteorological influences. This indicates that there are other drivers in the lower atmosphere that significantly influence the variability of the ionosphere. For example, the four-peaked structures (wave number 4 variation) of the eastward propagating zonal wave number 3 diurnal tide (DE3) component was found to modify the $E$ region dynamo [Immel et al., 2006; Jin et al., 2008; Ren et al., 2009; England et al., 2006]. Another type of meteorological event which is subject of our interest and responsible for the vertical coupling of the lower atmosphere with the upper atmosphere is sudden stratospheric warming (SSW). It is a large scale meteorological disturbance characterized by sudden deceleration or reverse in the direction of westerly winds in the winter period. It is an event accompanied by breakdown in the polar vortex and rapid 


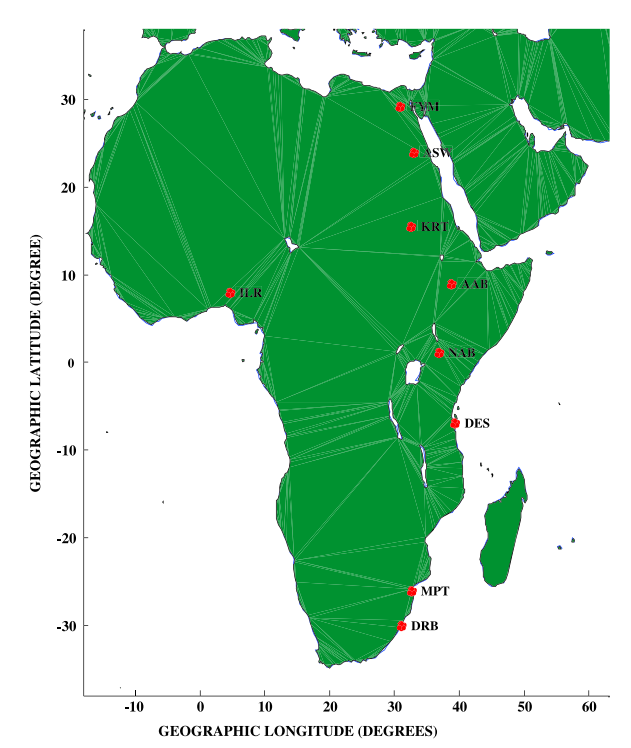

a: Location of nine MAGDAS stations investigated over Africa.

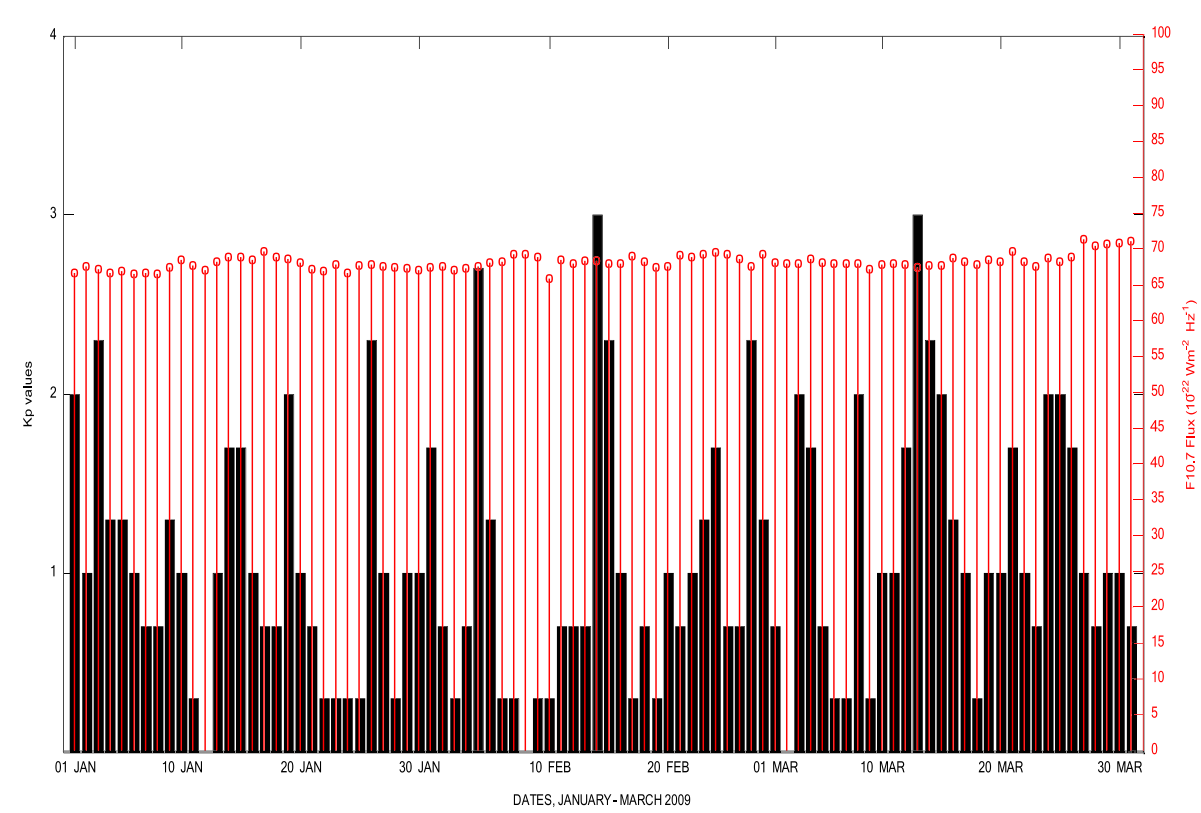

b: Geomagnetic and solar parameters; Kp and F10.7 for January - March, 2009.

Figure 1. (a) Location of nine MAGDAS stations investigated over Africa. (b) Geomagnetic and solar parameters; $K p$ and $F_{10.7}$ for January-March 2009.

rise in stratospheric temperature by several tens of degrees that last for several days or even a few weeks [Andrews et al., 1987]. The consequence of displaced stratospheric zonal flow interaction with the abnormally enhanced upward propagating waves at the cold pole is a large wave forcing from the lower atmosphere [Matsuno, 1971]. Limpasuvan et al. [2004] observed significant disturbance in the middle atmosphere that influences the upper atmosphere due to significant changes in the zonal and diurnal mean wind and the temperature height variations. Also, Goncharenko and Zhang [2008] for the first time found that the warming and cooling from the lower atmosphere extend to around altitude of $\sim 300 \mathrm{~km}$ and significantly influenced the upper atmosphere. They suggested that the modulation of the upper atmosphere that resulted from sudden stratospheric changes in the middle atmosphere, which significantly perturbed the ionosphere, could be considered as part of space weather. 
Table 1. Geographic and Geomagnetic Coordinates of the Stations Investigated

\begin{tabular}{|c|c|c|c|c|c|}
\hline \multirow[b]{2}{*}{ Station } & \multirow[b]{2}{*}{ Codes } & \multicolumn{2}{|c|}{ Geographic Coordinates } & \multicolumn{2}{|c|}{ Geomagnetic Coordinates } \\
\hline & & Latitude & Longitude & Latitude & Longitude \\
\hline Fayum & FYM & $29.30^{0}{ }^{\circ} \mathrm{N}$ & $30.84^{0^{\circ} \mathrm{E}}$ & $21.13^{0} \mathrm{o}$ & $102.34^{0^{\circ} \mathrm{E}}$ \\
\hline Aswan & ASW & $24.08^{0^{\circ} \mathrm{N}}$ & $32.89^{{ }^{\circ} \mathrm{E}}$ & $15.31^{0_{\circ}} \mathrm{N}$ & $104.77^{0_{\circ}} \mathrm{E}$ \\
\hline Khartoum & KRT & $15.63^{0^{\circ} \mathrm{N}}$ & $32.53^{0^{\circ}} \mathrm{E}$ & $6.03^{0}{ }^{\circ} \mathrm{N}$ & $104.00^{\circ} \mathrm{o}$ \\
\hline Addis Ababa & $A A B$ & $9.03^{0 \circ} \mathrm{N}$ & $38.74^{0}{ }^{\circ} \mathrm{E}$ & $0.16^{0} \mathrm{~N}$ & $110.44^{0_{\circ}} \mathrm{E}$ \\
\hline Ilorin & ILR & $8.50^{\circ} \mathrm{N}$ & $4.55^{0}{ }^{\circ} \mathrm{E}$ & $1.82^{0} \circ \mathrm{S}$ & $76.68^{0^{\circ}} \mathrm{E}$ \\
\hline Nairobi & NAB & $1.28^{0}{ }^{\circ} \mathrm{S}$ & $36.81^{\circ}{ }^{\circ} \mathrm{E}$ & $10.76^{0}{ }^{\circ} \mathrm{S}$ & $108.51^{0^{\circ}} \mathrm{E}$ \\
\hline Dal Es Salaam & DES & $6.80^{\circ \circ} \mathrm{S}$ & $39.28^{0}{ }^{\circ} \mathrm{E}$ & $16.62^{0 \circ} \mathrm{S}$ & $110.72^{0}{ }^{\circ} \mathrm{E}$ \\
\hline Maputo & MPT & $25.96^{0}{ }^{\circ} \mathrm{S}$ & $32.58^{0}{ }^{\circ} \mathrm{E}$ & $36.61^{0}{ }^{\circ} \mathrm{S}$ & $99.64^{0^{\circ} \mathrm{E}}$ \\
\hline Durban & DRB & $29.88^{0^{\circ} \mathrm{S}}$ & $31.05^{0}{ }^{\circ} \mathrm{E}$ & $39.51^{\circ}{ }^{\circ} \mathrm{S}$ & $96.41^{{ }^{\circ}} \mathrm{E}$ \\
\hline
\end{tabular}

Vineeth et al. [2009], Fejer et al. [2010], Stening [2011], Sridharan et al. [2009], Park et al. [2012], and Yamazaki et al. [2012a, 2012b, 2012c] studies have disclosed direct connections between $S_{q}$ of the horizontal $(H)$ magnetic field intensity $\left(\mathrm{S}_{q} H\right)$ and changes in the lower atmosphere over the low latitudes during the SSW events. These include significant changes in daytime EEJ, CEJ, semidiurnal signatures of $\mathrm{S}_{q} H$ current, lunar tides, equatorial mesospheric winds, and temperatures. Vineeth et al. [2009] observed that the EEJ and CEJ are strongly modified by diurnal tides, since EEJ and CEJ are mainly driven by the diurnal tide wind dynamo. They found CEJ and EEJ on days when diurnal tides are weakened and strengthened, respectively. This is in agreement with Fejer et al. [2010] results and further showed that the zonal mean wind reversal results in the enhancement of the lunar semidiurnal tidal winds. In the Africa sector, Yamazaki et al. [2012a] observed amplification in geomagnetic lunar tides at Addis-Ababa during SSW events that occurred between 1958 and 2007. Investigating $\mathrm{S}_{q} \mathrm{H}$ over 20 Asian stations during 2006 and 2009 SSW events, Yamazaki et al. [2012b] ascribed the EEJ and CEJ observed during the periods to the abnormal large tidal winds at the height of the dynamo region of the ionosphere. Further works of Yamazaki et al. [2012c] showed significant decrease and increase in the $S_{q} H$ equivalent current intensity over the Northern and Southern Hemispheres, respectively, along with a reduction in the longitudinal separation between the northern and southern current vortices.

It is obvious from the above literature that despite consistent investigations on the coupling of the lower and the upper atmosphere, which have unveiled a lot in the American and Asian sectors, little is known about SSW and $\mathrm{S}_{q} H$ characterization in the ionosphere above Africa. Therefore, this study provides a comprehensive analysis on $\mathrm{S}_{q} \mathrm{H}$ variability relating to coupling of the stratosphere and the ionosphere over Africa during 2009 SSW. In contrast to Vineeth et al. [2009], Stening [2011], Park et al. [2012], and Yamazaki et al. [2012a, 2012b, 2012c] works, we will analyze results, not only for when the zonal mean wind flow in the polar stratosphere reverses but also when it gradually weakens and gets to zero value. We will compare our results with previous studies from other regions and its equatorial characteristics with some stations in the American, Pacific, and Asian sectors.

\section{Materials and Methodology}

\subsection{Geophysical and Stratospheric Parameters}

Figure 1a shows the map of Africa with location of stations used in this study. Table 1 shows the list of station names, their codes, and geographic and geomagnetic coordinates. In order to understand the state of geomagnetic activity during these events, variations of the magnetic activity index $K_{p}$ and solar activity index $F_{10.7}$ obtained from the records of the (National Aeronautics and Space Administration (NASA) Space Physics Data Facility, http://omniweb.gsfc.nasa.gov/form/dx1.html) are included in our analysis (Figure 1b). We observed that the $K_{p}$ index (bar plots in black) on any of the days was low, the maximum value (2.9) was found on 14 February. The corresponding $F_{10.7}$ index (stem plots in red) is $\sim 72$.

The National Centers for Environmental Prediction-National Center for Atmospheric Research (NCEP-NCAR) reanalysis [Kalnay et al., 1996] for the year 2009 is used in this study. The data for NCEP-NCAR reanalysis can be downloaded from the website of the (National Oceanic and Atmospheric Administration (NOAA), office of Oceanic and Atmospheric Research, Earth System Research Laboratory, Physical Sciences Division, Boulder, Colorado, http://www.esrl.noaa.gov/psd/). The daily mean values of the zonal mean air temperature 
and the zonal mean zonal wind at $60^{\circ} \mathrm{N}$ and $10 \mathrm{hPa}$ (approximately $32 \mathrm{~km}$ ) were used to examine the variability of the 2009 SSW event from January to March periods.

The beginning of the 2009 SSW event according to the World Meteorological Organization (WMO) standard was attained on 18 January 2009. This is when the stratospheric (at an altitude of $10 \mathrm{hPa}$ pressure level) temperature at the northern polar latitudes (poleward of $60^{\circ} \mathrm{N}$ ) increased by more than $25 \mathrm{~K}$ within a week (Figure 2a). As a result of this, we have categorized the zonal mean air temperature of the stratosphere into six phases: (1) SSW precondition, when the temperature of the stratosphere is normal without any noticeable surge (3-17 January); (2) SSW ascending phase, when there is a surge in the temperature of the stratosphere (18-21 January); (3) SSW peak phase, when the surge in the temperature of the stratosphere is strongest (22-24 January); (4) SSW Descending Phase, when the surge in temperature of the stratosphere, which is strongest begins subsiding (25-31 January); (5) after the SSW, when the stratosphere recovered from the surge of the strongest temperature (1-25 February); and (6) No SSW, when the stratospheric temperature variability is similar to SSW precondition (28 February to 31 March). There were no March data available; hence, we restricted our no SSW phase to 28 February. The average of all the available data for each of the SSW phase was estimated to produce the error bar shown with Figures 2bi-2bvi.

Figure $2 \mathrm{c}$ illustrates the strength of the $2009 \mathrm{SSW}$ event. The zonal mean zonal wind at $60^{\circ} \mathrm{N}$ and $10 \mathrm{hPa}$ reverses westward on 24 January after the stratospheric air temperature reached peak value of $\sim 256 \mathrm{~K}$ on 23 January and the zonal mean wind value is zero. This indicates that the 2009 SSW event is a major one [Andrews et al., 1987]. The zonal mean wind value was highest $(\sim-29 \mathrm{~m} / \mathrm{s})$ on 29 January and subsided afterward but remained easterly until 22 February.

\subsection{Magnetic Data Acquisition System Data Set}

The ground-based magnetometer that archived the horizontal $(H)$ magnetic field is obtained from nine Magnetic Data Acquisition System (MAGDAS) stations in the African chain, covering both the Northern and Southern Hemispheres. These station distributions in geographical latitudes spanned between $\sim 30^{\circ} \mathrm{N}$ and $\sim 30^{\circ} \mathrm{S}$ (Table 1 and Figure 1) and are available at International Centre for Space Weather Science and Education (ICSWSE) website at www.serc.kyushu-u.ac.jp/data/. Other magnetic data used to further investigate the longitudinal variations of $\mathrm{S}_{q} \mathrm{H}$ during 2009 SSW in the South America (Huancanyo, HUA, geomagnetic coordinates: $0.6^{\circ} \mathrm{S}, 355.46^{\circ} \mathrm{W}$ ), Pacific Ocean (Pohnpei, PON, geomagnetic coordinates: $0.25^{\circ}{ }^{\circ} \mathrm{N}$, $229.11^{\circ} \mathrm{E}$ ), and Central Asia (Trivandrum, TIR, geomagnetic coordinates: $0.34^{\circ}{ }^{\circ} \mathrm{N}$ and $148.82^{\circ}{ }^{\circ} \mathrm{E}$ ) are retrieved from (International Real-time Magnetic Observatory Network, http://www.intermagnet.org/data-donnee/ dataplot-eng.php?type=hdz), (Japan Agency for Marine-Earth Science and Technology, http://p21.jamstec. go.jp/geom/), and (Indian Institute of Geomagnetism, http://wdciig.res.in/WebUl/Home.aspx), in that order. The 1 min resolution of the $\mathrm{H}$ component of these geomagnetic field data obtained is binned into hourly values. The observed $\mathrm{H}$ component of the geomagnetic field perturbations at the ground is induced with the local magnetic perturbations at the ground and the global magnetic perturbations associated with magnetospheric currents [Fukushima and Kamide, 1973]. To solve this issue, the global contributions due to magnetospheric currents are removed from the hourly $\mathrm{H}$ component of the geomagnetic field by subtracting the hourly values of the (disturb storm time) Dst index from it. Mathematically, this is expressed as

$$
\Delta H_{\text {ground }}=H_{\text {local }}-M_{H},
$$

where $H_{\text {local }}$ is the observed $\mathrm{H}$ component of the geomagnetic field perturbations at any particular hour and $M_{H}=D s t \operatorname{Cos}(L)$ is the calculated value effect of Dst index, provided by the (World Data Centre for Geomagnetism, Kyoto at http://wdc.kugi.kyoto-u.ac.jp) for the same particular hour, where $L$ is the geomagnetic latitude of the stations.

To quantify the $S_{q} H$ current, the averaged nocturnal values between 2400 LT and 0100 LT for a particular day (base line value) are subtracted from the hourly values of $\Delta H_{\text {ground }}$ for that particular day [Vestine, 1947; Rabiu et al., 2009; Bolaji et al., 2013]. Therefore, for a particular hour for a day, $S_{q} H$ current for a station is

$$
S_{q} H_{t}=H_{t}-\mathrm{BLV},
$$

where $t$ is the time in hours, $H_{t}$ is the $\Delta H_{\text {ground }}$ value at that time, BLV is the base line value for that day, and $S_{q} H_{t}$ is the estimated $S_{q} H$ value for that hour $t$. In order to achieve the aforementioned phases described in section 2.1, the daily variability of $S_{q} H$ was averaged into these six SSW phases. 


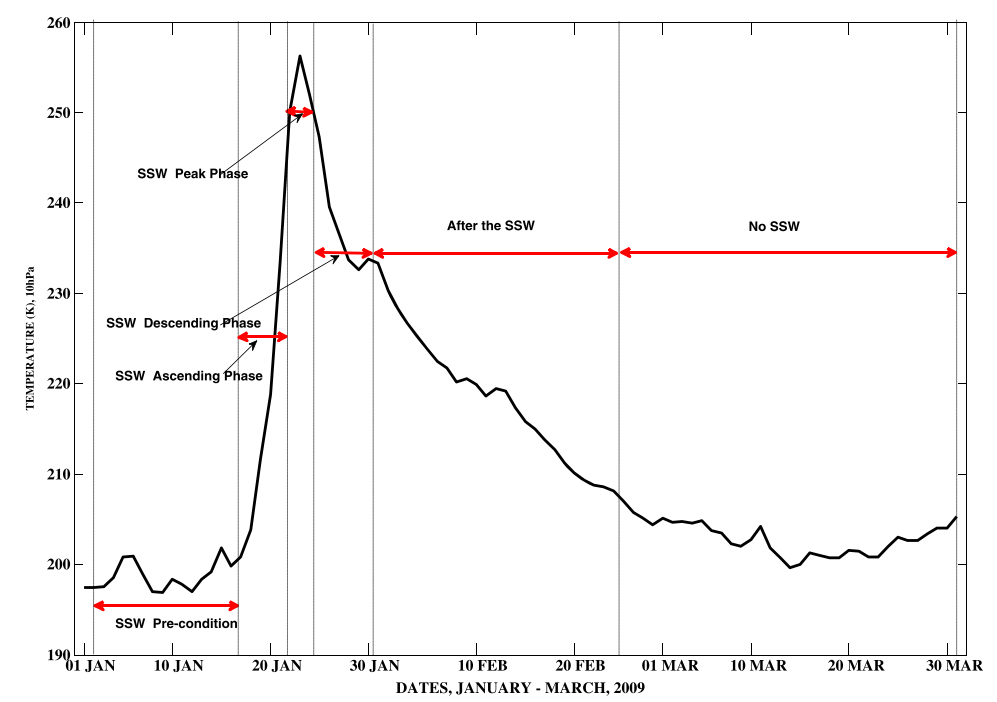

a: Stratospheric zonal mean air temperature for January - March, 2009 showing the SSW Precondition, SSW Ascending, SSW Peak, SSW Descending, After the SSW and No SSW Phase.
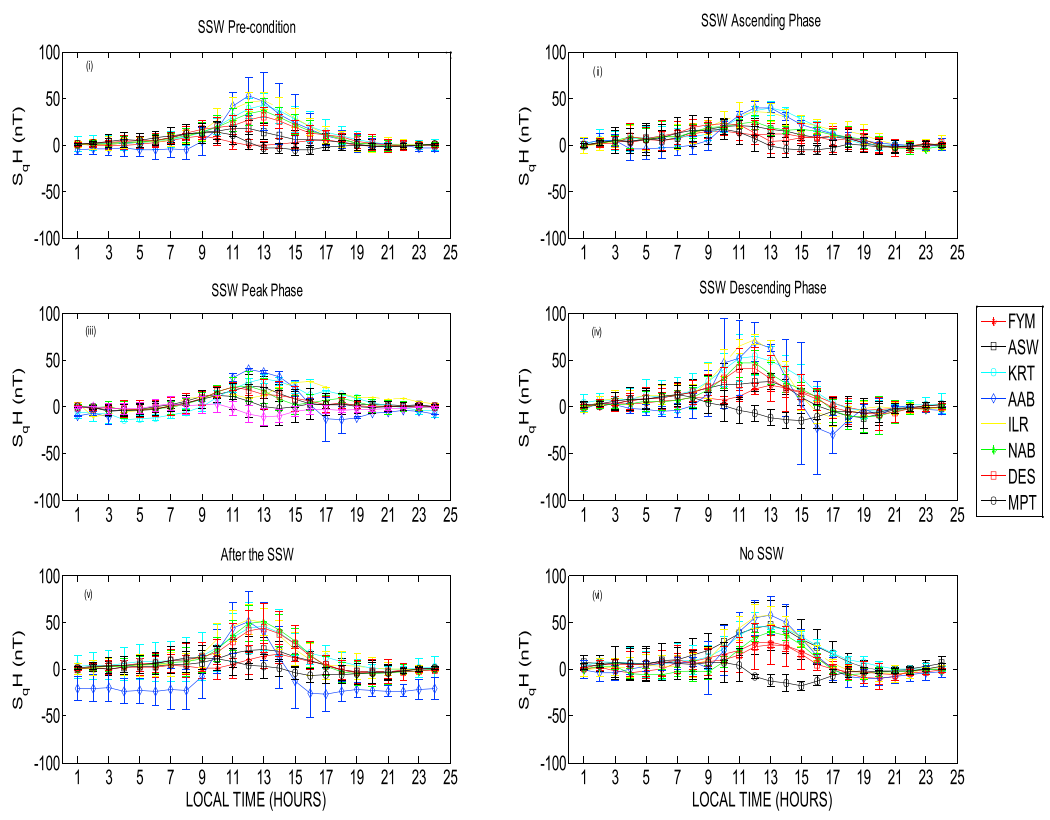

b: Error bar of all the available data

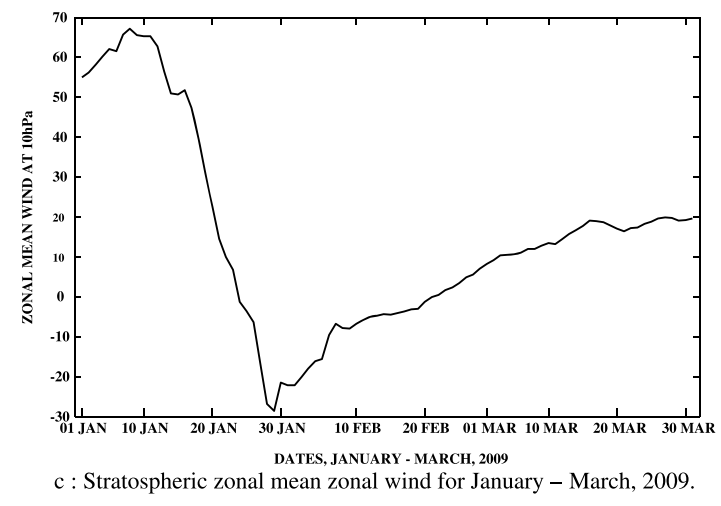

Figure 2. (a) Stratospheric zonal mean air temperature for January-March 2009 showing the SSW precondition, SSW ascending, SSW peak, SSW descending, after the SSW, and no SSW Phase. (b) Error bar of all the available data. (c) Stratospheric zonal mean zonal wind for January-March 2009. 


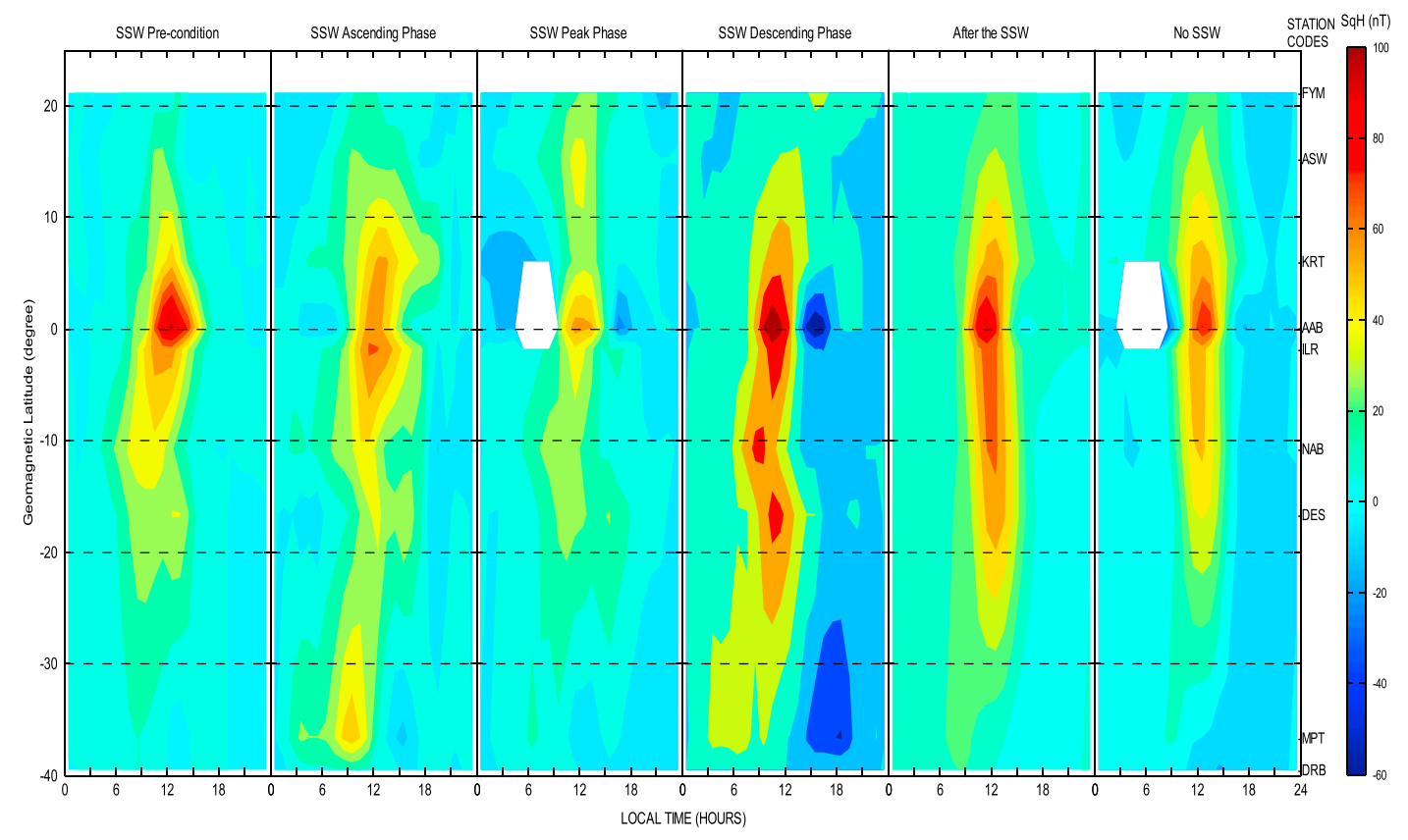

Figure 3. Two-dimensional plot of $S_{q}(H)$ as a function of local time across nine stations in Africa during the year 2009 SSW event.

\section{Results and Discussion}

A two-dimensional plot with grid lines on the $y$ axis (Figure 3 ) shows the latitudinal profile of $S_{q} H$ variability between $3^{\circ}$ and $40^{\circ}$ east of the African sector. The geomagnetic latitudes of the stations under investigation are presented on the $y$ axis and arranged in increasing order from the Southern to Northern Hemisphere. The $x$ axis shows the daily varying local time (LT) of each phase in hours. The white background in the twodimensional plot is due to a number of data gaps that result from interruptions in the data recording, mostly due to power interruptions. The colored bar beside the two-dimensional plot shows the magnitudes of $S_{q} H$ in nanotesla (nT). The time series plots of $S_{q} H$ of three-equatorial stations at different longitudes in the South America (HUA), Pacific Ocean (PON), and Central Asia (TIR) sectors are shown in Figure 4.

\subsection{Latitudinal Variations of $S_{q} H$ Current Due To 2009 SSW Over Africa}

In all the phases (Figure 3 ) at the dip equator, highest magnitudes of the $S_{q} H$ straddled Addis-Ababa (AAB) and Ilorin (ILR) in the daytime between $1100 \mathrm{LT}$ and $1300 \mathrm{LT}$. The highest magnitude at AAB during the SSW precondition, SSW peak phase, SSW descending phase, after the SSW, and when there is no SSW in place is $\sim 93 \mathrm{nT}, \sim 51 \mathrm{nT}, \sim 99 \mathrm{nT}, \sim 88 \mathrm{nT}$, and $\sim 80 \mathrm{nT}$, in that order. The highest $S_{q} H$ magnitude of $\sim 61 \mathrm{nT}$ was observed at ILR during the SSW ascending phase. This indicate that the $S_{q} H$ peak which is significant near noon hours at $A A B\left(0.18^{\circ} \mathrm{S}\right.$ of geomagnetic latitude) in all the SSW phases considered was absent during the SSW ascending phase. During this SSW ascending phase when $S_{q} H$ is maximum at ILR $\left(1.82^{\circ}{ }^{\circ} \mathrm{S}\right.$ of the geomagnetic latitude), the stratosphere is characterized by weakened zonal mean wind (Figure $2 \mathrm{c}$ ) and a surge in the temperature more than $25 \mathrm{~K}$ within a week (Figure $2 \mathrm{a}$ ).

It is worthy to note that this is a clearer evidence of modified $\mathrm{S}_{q} H$ at the dip equator due to SSW and contrast the quiet period morphology of $S_{q} H$ current intensity at the dip equator revealed by Matsushita [1967] and the study of longitudinal difference in the EEJ current over the African sector by Rabiu et al. [2011]. Matsushita [1967] showed that $S_{q} H$ current intensity at the dip equator is a function of how closer a station is to the dip equator. The closer a station to the dip equator, the more intense the $S_{q} H$ magnitude when there is no SSW. Also, longitudinal variations in the Earth magnetic field have been investigated by Doumouya et al. [2003], Doumouya and Cohen [2004], and Chandrasekhar et al. [2014] when there is no influence due to SSW. Doumouya et al. [2003] and Doumouya and Cohen [2004] found secondary maximum and minimum in EEJ currents over the West African (western axis) and Atlantic sector (eastern axis), respectively. Chandrasekhar 

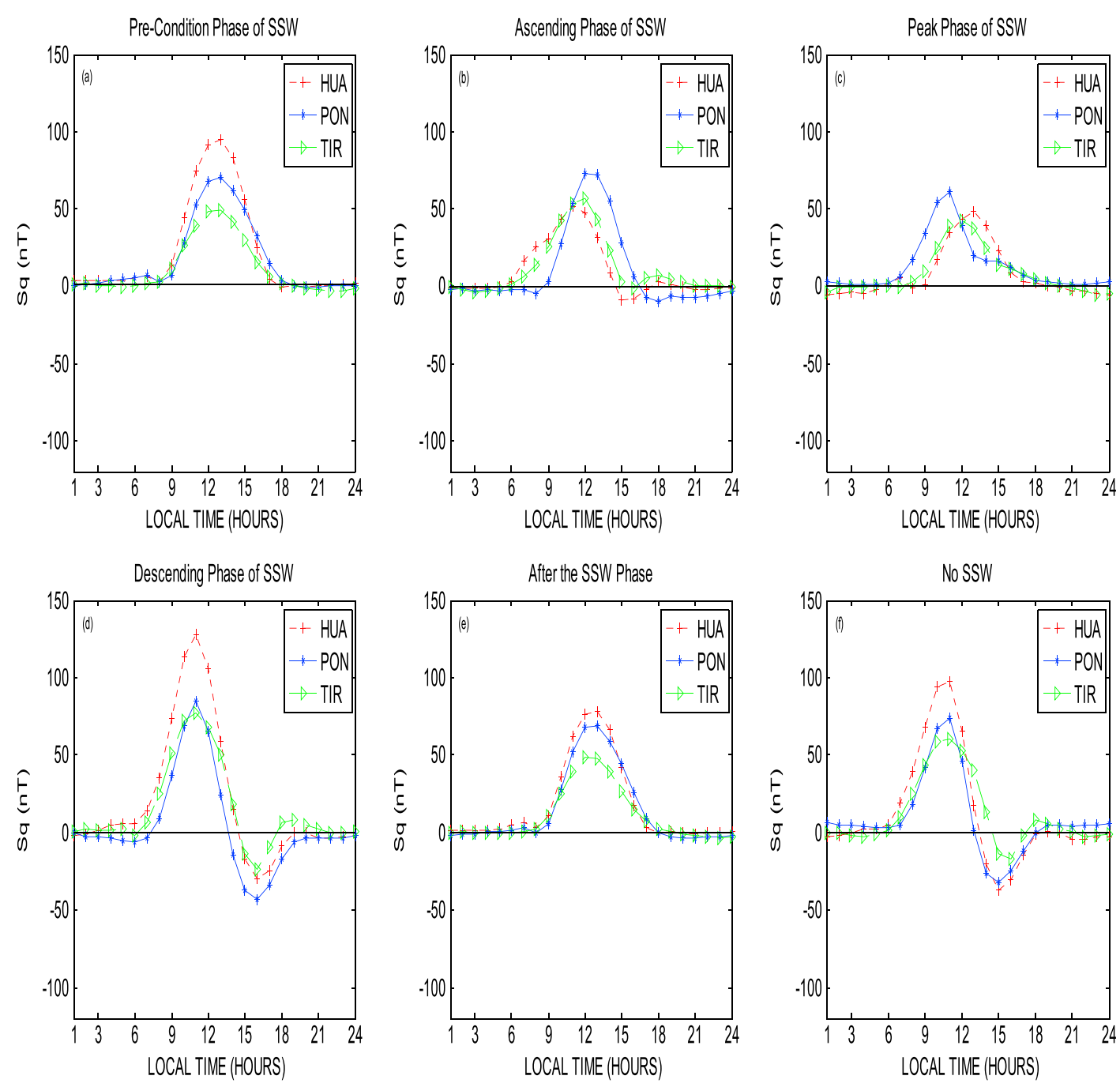

Figure 4. Variability of $\mathrm{S}_{q} \mathrm{H}$ at equatorial stations in South America (Huacanyo, HUA), Pacific Ocean (Phonpei, PON), and Asia (Trivandrum, TIR) sectors during (a) precondition phase of SSW, (b) ascending phase of SSW, (c) peak phase of SSW, (d) descending phase of SSW, (e) after the SSW phase, and (f) no SSW in 2009.

et al. [2014] showed that EEJ current is strongest in South America sector (western axis) and weakest in India sector (eastern axis). In the worldwide context summary, magnetic field variations are stronger in the western than the eastern axis. This is due to a stronger background magnetic field [Shinbori et al., 2010] at the eastern axis that produce lower ionospheric conductivity compared to the western axis. However, a detailed study of the EEJ current made by Rabiu et al. [2011] in the African sector revealed that the western EEJ is weaker than the eastern EEJ. They suggested that there is a possibility of reinjection of energy in the jet as it flows eastward. To clarify this arguments, we further carried out investigations on longitudinal variability of $S_{q} H$ during 2009 SSW episode at some equatorial stations around the world. These will be discussed later in section 3.2 .

Irrespective of higher $\mathrm{S}_{q} \mathrm{H}$ magnitude found at $\mathrm{AAB}$ during the $\mathrm{SSW}$ peak phase, further reduction in $\mathrm{S}_{q} \mathrm{H}$ value $(\sim 39 \mathrm{nT})$ is significant at ILR. This is interesting and indicates that the $S_{q} H$ magnitudes over the magnetic equator ( $A A B$ and ILR) and across the hemispheres were further depleted during the SSW peak phase compared to all the SSW phases under investigation.

The effort of Liu and Roble [2002] using a self-generated SSW model of coupled Thermosphere lonosphere Mesosphere Electrodynamics-General Circulation Model/Community Climate Model-3 (TIME-GCM/CCM3) has shown that the decelerating stratospheric zonal mean wind (during the SSW ascending phase) would 
initiate significant upward propagation of the westward propagating gravity and planetary waves (quasi 16 day wave) as it approaches zero level. The intensity of the upward westward propagating gravity and planetary waves increases when the stratospheric zonal mean wind gets to zero level, which coincides with the SSW peak phase when the stratospheric air temperature is highest. This signifies that the upward propagation of these waves would modulate the tidal components (diurnal and semidiurnal) at the lower thermosphere either by enhancement [Sridharan et al., 2002] or reduction [Meyer, 1999] of the dynamo electric fields. Hence, the reduction in the magnitude of $S_{q} H$ during the SSW peak phase could be due to reduction of upward propagating tides from the middle atmosphere.

It is clearer from our results that this evidence regarding $S_{q} H$ reduction is beyond the middle atmosphere because the strong forcing from below due to SSW significantly influences the $S_{q} H$ hemispheric asymmetry at the upper atmosphere. For example, our results in Figures $2 \mathrm{a}, 2 \mathrm{c}$, and 3 established that when the stratospheric air temperature and stratospheric zonal mean wind get to the highest value $(\sim 256 \mathrm{~K}$ at $10 \mathrm{hPa})$ and zero level, respectively (SSW peak phase), the reduction of the tidal components were further strengthened compared to during the SSW ascending phase. Immediately after zero level (the SSW descending phase), the stratospheric air temperature decreases sharply, stratospheric zonal mean wind reduces further beyond zero (negative value), and the reduction of the tidal components subsides.

Northward from $A A B$ and southward from ILR, $S_{q} H$ magnitudes decrease across the latitude in the daytime near noon hours. The spread of $S_{q} H$ magnitudes in the daytime is higher in the Southern than the Northern Hemisphere in all the phases investigated with an exception during the SSW peak phase. For example, $S_{q} H$ magnitudes in the range of $\sim 40 \mathrm{nT}$ to $\sim 50 \mathrm{nT}$ terminated around $\sim 11^{0}$ in the Northern Hemisphere during the SSW precondition and SSW ascending phase. As can be observed in the Southern Hemisphere, $\mathrm{S}_{q} \mathrm{H}$ magnitude in the range of $\sim 40 \mathrm{nT}$ to $\sim 50 \mathrm{nT}$ is found at latitudes higher than $11^{\circ}$. In the SSW peak phase, which is an exception, $\sim 40 \mathrm{nT}$ of $S_{q} H$ magnitude straddled ASW. Between NAB and DES, where ASW could be found in the Southern Hemisphere, $S_{q} H$ magnitude is $\sim 28 \mathrm{nT}$.

Our results during the SSW peak phase contrast the works of Yamazaki et al. [2012c] that investigated similar 2009 SSW event in the late December of 2008 and middle February of 2009 over the American and Asian sectors. They reported decrease and increase in the northern and southern $S_{q} H$ current intensities, respectively. This higher $\mathrm{S}_{q} H$ in the Southern Hemisphere is a robust feature due to higher solar zenith angle in the local summer hemisphere that initiated the greater electrical conductivity [Yamazaki et al., 2012c]. We suggest that weaker electrical conductivity during the SSW peak phase that initiated reduced $\mathrm{S}_{q} H$ is prone to meridional modulation that could initiated unusual hemispheric asymmetry in $S_{q} H$ (higher values of $S_{q} H$ magnitudes in the Northern Hemisphere compared to the Southern Hemisphere) over the African sector.

Around $1300 \mathrm{LT}$ at the dip equator, decreases in $\mathrm{S}_{q} \mathrm{H}$ magnitudes were observed and later reversed to negative values in the evening period $(1500 \mathrm{LT}-1800 \mathrm{LT})$. This afternoon reversal in $S_{q} H$ from positive to negative value that signify afternoon counter electrojet (CEJ) at the dip equator was absent during the SSW precondition, SSW ascending phase, and after the SSW. In the SSW peak phase, no CEJ was seen over ILR and the maximum CEJ seen over $A A B$ at $1700 \mathrm{LT}$ is -25 nT. The maximum CEJ magnitude found at $A A B(1600$ LT) and ILR (1700 LT) during the SSW descending phase is $\sim-58 \mathrm{nT}$ and $\sim-20 \mathrm{nT}$, respectively. Also, during the No SSW in the evening, $\sim-12 \mathrm{nT}$ value of $S_{q} H$ was recorded as maximum at $1800 \mathrm{LT}$ over AAB. It is clearer from our results that the afternoon CEJ observed at AAB during the No SSW, SSW peak, and SSW descending phase is low, moderate, and high, respectively.

With these results, we confirmed earlier reports made by Vineeth et al. [2007] and Yamazaki et al. [2012b] that SSW-triggered additional currents (strengthening of the EEJ) and CEJ magnitudes at equatorial stations. This similarity in results is possible since these researchers investigated $S_{q} H$ variability when the zonal mean wind reverses (SSW descending phase) and compared it with SSW precondition. Also, the effects of these additional currents found at the dip equator of Africa were seen over the low and middle latitude across the Southern Hemisphere. Interestingly, their effects during the SSW descending phase compared to No SSW phase are increased $S_{q} H$ magnitudes near noon hours and additional westward currents around $1300 \mathrm{LT}$ over the low and middle latitude of the Southern Hemisphere. Although, Campbell and Schiffmacher [1985, 1988], Takeda [2002], Chen et al. [2008], El Hawary et al. [2012], and Bolaji et al. [2015] have investigated hemispheric variability of $S_{q}$ currents over Africa, America, and Asia sectors. They suggested that southward $S_{q}$ focus in the 
Southern Hemisphere is characterized by westward currents in the daytime. However, these additional westward currents observed from our results that mapped over the Southern Hemisphere of the low latitude and became intensified around the middle latitude (MPT and DRB) are clearer evidences that the lower atmospheric effect due to SSW significantly perturbed the upper atmosphere.

The morning CEJ $(0700 \mathrm{LT}-0900 \mathrm{LT})$ seen during the SSW ascending phase at $A A B$ have a maximum value of $\sim-7 \mathrm{nT}$ at $0700 \mathrm{LT}$. During No SSW phase, the morning CEJ found at AAB around $0900 \mathrm{LT}$ is $-29 \mathrm{nT}$. These show that morning CEJ is gradually suppressed as the zonal mean air temperature is increasing and no CEJ is visible when the stratospheric zonal mean wind reverses easterly.

\subsection{Longitudinal Variations of $S_{q} H$ Current Due To 2009 SSW Over South America (HUA), Pacific Ocean (PON), and Central Asia (TIR) Sectors}

Figure 4 depicts the $S_{q} H$ variations at different longitudes (HUA, PON, and TIR) within the dip equator for 2009 SSW episode. We observed that the $S_{q} H$ variations during the SSW ascending, peak, and descending phases depict characteristics similar to that observed in the African sector. These similarities in characteristics are reduced $\mathrm{S}_{q} \mathrm{H}$ values during the SSW ascending phases that are further strengthened during SSW peak phases in all the stations compared to the SSW preconditions. Also, enhanced $\mathrm{S}_{q} H$ magnitudes associated with CEJ found within the African dip equator during the descending phase compared to other phases were as well observed at other longitudes (HUA, PON, and TIR). Therefore, all longitudes investigated during 2009 SSW event are characterized by enhanced EEJ associated with CEJ [Vineeth et al., 2009; Yamazaki et al., 2012b] during the descending phases and significantly reduced $\mathrm{S}_{q} \mathrm{H}$ magnitudes during the SSW peak phases. This indicates that during SSW peak phases, reduction of upward propagating tides at the lower thermosphere from the middle atmosphere is on worldwide scale. One obvious longitudinal feature found in all the phases with SSW ascending phase as an exception that further clarifies the controversial western and eastern axes issues [Doumouya et al., 2003; Doumouya and Cohen, 2004; Chandrasekhar et al., 2014] is that $\mathrm{S}_{q} \mathrm{H}$ variability is highest, higher, and high at the South America, Africa, and Pacific Ocean sectors, respectively. Also, the $S_{q} H$ variability is relatively weaker over the Asian sector.

As far as Rabiu et al. [2011] results on EEJ variations within the African sector, we suggest that they are strongly influenced by the choice of location. The AAB station is closer to the geomagnetic dip equator than ILR station, which could result in higher EEJ strength in the eastern axis compared to the western axis. It is also a well-known fact that the geomagnetic main field with respect to the dip equator in the South America (almost vertical) and African (almost horizontal) longitudes are different and in-turn have different morphologies. Hence, the strongest $S_{q} H$ magnitudes found in the South American sector compared to other sectors. Apart from the stronger background magnetic field [Shinbori et al., 2010] at the eastern axis that could initiate these relatively weaker $S_{q} H$ found at TIR, Hartman and Heelis [2007] and Fang et al. [2012] observations on the closeness of the Indian longitude to region where the magnetic declination angle of the Earth's magnetic field is negative along the magnetic equator are factors that could contribute to these reductions. The influence of magnetic induction due to ocean effect on PON with relatively higher $S_{q} H$ variability compared to TIR cannot be overlooked. Kuvshinov et al. [2007] suggested similar ocean effect on $S_{q} H$ variations that showed relatively higher magnitudes near noon hour over south Indian electrojet where the EEJ plays insignificant role in the large value near noon hour.

\section{Conclusions}

Our results reveal significant changes in the $S_{q} H$ over the African chain due to the 2009 SSW event. We found a different morphology of $S_{q} H$ current intensity during the SSW peak phase, where the $S_{q} H$ current intensity in the Northern Hemisphere is significantly stronger than the Southern Hemisphere. This is in sharp contrast to the work of Yamazaki et al. [2012c] which reported that the observed changes in the $S_{q} H$ current are characterized by a decrease and increase of the $S_{q} H$ current intensity in the Northern and Southern Hemispheres, respectively. Significant decrease in $\mathrm{S}_{q} H$ during SSW peak phase over the African hemispheres is revealed. This decrease is also confirmed at the dip equator of South America, Pacific Ocean, and Central Asia sectors. This needs further investigation over the hemispheres of the low latitude at other regions. The greater $\mathrm{S}_{q} \mathrm{H}$ variability in the western axis compared to the eastern axis [Doumouya et al., 2003; Doumouya and Cohen, 2004; Chandrasekhar et al., 2014] is confirmed. 


\section{Acknowledgments}

The Magnetic Data Acquisition System (MAGDAS) data used for this paper are available at International Centre for Space Weather Science and Education (ICSWSE) website (www.serc.kyushu-u. ac.jp/data/) upon request from the Project Leader (PL) of MAGDAS/CPMN observations, A. Yoshikawa (e-mail address: yoshi@geo.kyushu-u.ac.jp). Authors acknowledge the support of the Japan Society for the Promotion of Science (JSPS) Core-to-Core Program, B. Asia-Africa Science Platforms. The MAGDAS/CPMN group at International Centre for Space Weather Science and Education (ICSWSE), Kyushu University, Japan, and all hosts of MAGDAS facilities across Africa are acknowledged for keeping records of magnetic data and making them available for this study. The authors acknowledged the anonymous reviewers for their suggestions that improved this work.
This study focuses on temporal variations in $\mathrm{S}_{q} \mathrm{H}$ and their changes in the context of different phases of SSW. Alternative interpretation to different phases of SSW is the SSW-related variations in ionospheric parameters in terms of their timing as compared to lunar cycle [Fejer and Tracy, 2013; Pedatella et al., 2014]. Hence, it will be interesting to look at other cases of SSW due to lunar cycle and during different phases since one cannot make conclusions from one case study of a SSW event.

\section{References}

Andrews, D., J. R. Holton, and C. B. Leovy (1987), Middle Atmosphere Dynamics, pp. 259-294, Elsevier, New York.

Baker, W. G., and D. F. Martyn (1953), Electric currents in the ionosphere, I. The conductivity, Philos. Trans. R. Soc., A246, 281-294, doi:10.1098/ rsta.1953.0016.

Bolaji, O. S., J. O. Adeniyi, I. A. Adimula, S. M. Radicella, and K. Yumoto (2013), Total electron content and magnetic field intensity over llorin, Nigeria, J. Atmos. Sol. Terr. Phys., 98, 1-11, doi:10.1016/j.jastp.2013.02.011.

Bolaji, O. S., A. B. Rabiu, O. R. Bello, A. Yoshikawa, K. Yumoto, O. O. Odeyemi, and O. O. Ogunmodimu (2015), Spatial variability of solar quiet fields along $96^{\circ}$ magnetic meridian in Africa: Results from MAGDAS, J. Geophys. Res. Space physics, 120, 3883-3898, doi:10.1002/2014JA020728.

Campbell, W. H., and E. R. Schiffmacher (1985), Quiet ionospheric currents of the northern hemisphere derived from quiet field records, J. Geophys. Res., 90, 6475-6486, doi:10.1029/JA090iA07p06475.

Campbell, W. H., and E. R. Schiffmacher (1988), Quiet ionospheric currents of the southern hemisphere derived from quiet field records, J. Geophys. Res., 93(A2), 933-944, doi:10.1029/JA093iA02p00933.

Chandrasekhar, N. P., K. Arora, and N. Nagarajan (2014), Characterization of seasonal and longitudinal variability of EEJ in the Indian region, J. Geophys. Res. Space Physics, 119, 10,242-10,259, doi:10.1002/2014JA020183.

Chen, C. H., J. Y. Liu, K. Yumoto, C. H. Lin, and T. W. Fang (2008), Equatorial ionization anomaly of total electron content and equatorial electrojet in ground-based geomagnetic field strength, J. Atmos. Sol. Terr. Phys., 70, 2172-2183, doi:10.1016/j.jastp.2008.09.021.

Doumouya, V., and Y. Cohen (2004), Improving and testing the empirical equatorial electrojet model with CHAMP satellite data, Ann. Geophys., 22, 3323-3333, doi:10.5194/angeo-22-3323-2004.

Doumouya, V., Y. Cohen, B. R. Arora, and K. Yumoto (2003), Local time and longitude dependence of the equatorial electrojet magnetic effects, J. Atmos. Sol. Terr. Phys., 65(14-15), 1265-1282, doi:10.1016/j.jastp.2003.08.014.

El Hawary, R., et al. (2012), Annual and semi-annual Sq variations at $96^{\circ}$ MM MAGDAS I and II stations in Africa, Earth Planets Space, 64 , 425-432, doi:10.5047/eps.2011.10.013.

England, S. L., S. Maus, T. J. Immel, and S. B. Mende (2006), Longitudinal variation of the $E$-region electric fields caused by atmospheric tides, Geophys. Res. Lett., 33, L21105, doi:10.1029/2006GL027465.

Fang, T., T. Rowell, R. Akmaev, F. Wu, H. Wang, and D. Anderson (2012), Longitudinal variation of ionospheric vertical drifts during the 2009 sudden stratospheric warming, J. Geophys. Res., 117, A03324, doi:10.1029/2011JA07348.

Fejer, B. . G., and B. . D. Tracy (2013), Lunar tidal effects in the electrodynamics of the low latitude ionosphere, J. Atmos. Sol. Terr. Phys., 103, 76-82, doi:10.1016/j.jastp.2013.01.008.

Fejer, B. G., M. E. Olson, J. L. Chau, C. Stolle, H. Lühr, L. P. Goncharenko, K. Yumoto, and T. Nagatsuma (2010), Lunar-dependent equatorial ionospheric electrodynamic effects during sudden stratospheric warmings, J. Geophys. Res., 115, A00G03, doi:10.1029/2010JA015273.

Fukushima, N., and Y. Kamide (1973), Partial ring current models for worldwide geomagnetic disturbances, Rev. Geophys. Space Phys., 11, 795-853, doi:10.1029/RG011i004p00795

Goncharenko, L. P., and S. R. Zhang (2008), lonospheric signatures of sudden stratospheric warming: lon temperature at middle latitude, Geophys. Res. Lett., 35, L21103, doi:10.1029/2008GL035684.

Gouin, P., and P. N. Mayaud (1967), A propos de l'existence possible d'un contre electrojet aux latitudes magnetiques equatoriales, Ann. Geophys., 23, 41-47.

Hartmann, W. A., and R. A. Heelis (2007), Longitudinal variations in the equatorial vertical drift in the topside ionosphere, J. Geophys. Res., 112, A03305, doi:10.1029/2006JA011773.

Immel, T. J., E. Sagawa, S. L. England, S. B. Henderson, M. E. Hagan, S. B. Mende, H. U. Frey, C. M. Swenson, and L. J. Paxton (2006), Control of equatorial ionospheric morphology by atmospheric tides, Geophys. Res. Lett., 33, L15108, doi:10.1029/2006GL026161.

Jin, H., Y. Miyoshi, H. Fujiwara, and H. Shinagawa (2008), Electrodynamics of the formation of ionospheric wave number 4 longitudinal structure, J. Geophys. Res., 113, A09307, doi:10.1029/2008JA013301.

Kalnay, E., M. Kanamitsu, R. Kistler, and W. Collins (1996), The NCEP/NCAR 40-year reanalysis project, Bull. Am. Meteorol. Soc., 77(3), 437-471.

Kuvshinov, A., C. Manoj, N. Olsen, and T. Sabaka (2007), On the induction effects of geomagnetic daily variations from equatorial electrojet and solar quite sources at low and middle latitudes, J. Geophys. Res., 112, B10102, doi:10.1029/2007JB004955.

Limpasuvan, V., D. W. J. Thompson, and D. L. Hartmann (2004), The life cycle of the northern hemisphere sudden stratospheric warmings, J. Clim., 17, 2584-2596, doi:10.1175/1520-0442(2004)017<2584:TLCOTN>2.0.CO;2.

Liu, H. L., and R. G. Roble (2002), A study of a self - generated stratospheric sudden warming and its mesospheric - lower atmospheric impacts using the coupled TIME-GCM/CCM3, J. Geophys. Res., 107(D23), 4695, doi:10.1029/2001JD001533.

Matsuno, T. (1971), A dynamical model of the stratospheric sudden warning, J. Atmos. Sci., 28, 1479-1494.

Matsushita, S. (1967), Solar quiet and lunar daily variation fields, in Physics of Geomagnetic Phenomena, edited by S. Matsushita and W. Campbell, chap. II-I, pp. 301-424, Academic, New York.

Meyer, C. K. (1999), Gravity wave interactions with the diurnal propagating tide, J. Geophys. Res., 104, 4223-4239, doi:10.1029/ 1998JD200089.

Onwumechili, C. A. (1967), Geomagnetic variations in the equatorial zone, in Physics of Geomagnetic Phenomenona, vol. 1, edited by S. Matsushita and W. H. Campbell, 425 pp., Academic, New York.

Park, J., H. Lühr, M. Kunze, B. G. Fejer, and K. W. Min (2012), Effect of sudden stratospheric warming on lunar tidal modulation of the equatorial electrojet, J. Geophys. Res., 117, A03306, doi:10.1029/2011JA017351.

Pedatella, N. M., H.-L. Liu, F. Sassi, J. Lei, J. L. Chau, and X. Zhang (2014), lonosphere variability during the 2009 SSW: Influence of the lunar semidiurnal tide and mechanisms producing electron density variability, J. Geophys. Res. Space Physics, 119, 3828-3843, doi:10.1002/ 2014JA019849.

Rabiu, A. B., I. A. Adimula, K. Yumoto, J. O. Adeniyi, and G. O. Maeda (2009), MAGDAS/CPMN project group, Earth Moon Planet., 104, doi:10.1007/s11038-008-9290-7. 
Rabiu, A. B., K. Yumoto, E. O. Falayi, O. R. Bello, and MAGDAS/CPMN Group (2011), lonosphere over Africa: Results from geomagnetic field measurements during International Heliophysical Year IHY, Sun Geosphere, 6(2), 63-66.

Ren, Z., W. Wan, L. Liu, and J. Xiong (2009), Intra-annual variation of wave number 4 structure of vertical $E \times B$ drifts in the equatorial ionosphere seen from ROCSAT-1, J. Geophys. Res., 114, A05308, doi:10.1029/2009JA014060.

Richmond, A. D., and R. G. Roble (1987), Electrodynamic effects of thermospheric winds from the NCAR thermospheric general circulation model, J. Geophys. Res., 92, 12,365-12,376, doi:10.1029/JA092iA11p12365.

Shinbori, A., et al. (2010), Anomalous occurrence feature of the preliminary impulse of geomagnetic sudden commencement in the South Atlantic anomaly region, J. Geophys. Res., 115, A08309, doi:10.1029/2009JA015035.

Shiokawa, K., Y. Otsuka, and T. Ogawa (2009), Propagation characteristics of nighttime mesospheric and thermospheric waves observed by optical mesosphere thermosphere imagers at middle and low latitudes, Earth Planets Space, 61(4), 479-491, doi:10.1186/BF03353165.

Sridharan, S., S. Gurubaran, and R. Rajaram (2002), Structural changes in the tidal components in mesospheric winds as observed by the MF radar during afternoon counter electrojet events, J. Atmos. Sol. Terr. Phys., 64, 1455-1463, doi:10.1016/S1364-6826(02)00109-8.

Sridharan, S., S. Sathishkumar, and S. Gurubaran (2009), Variabilities of mesospheric tides and equatorial electrojet strength during major stratospheric warming events, Ann. Geophys., 27, 4125, doi:10.5194/angeo-27-4125-2009.

Stening, R. J. (2011), Lunar tide in the equatorial electrojet in relation to stratospheric warmings, J. Geophys. Res., 116, A12315, doi:10.1029/ $2000 \mathrm{JA000175.}$

Takeda, M. (2002), Features of global geomagnetic $S_{q}$ field from 1980 to 1990, J. Geophys. Res., 107(A9), 1252, doi:10.1029/2001JA009210.

Vestine, E. (1947), The Geomagnetic Field, its Description and Analysis, 580 pp., Carnegie Institute, Washington Publ., Washington, D. C.

Vineeth, C., T. K. Pant, C. V. Devasia, and R. Sridharan (2007), Highly localized cooling in daytime mesopause temperature over the dip equator during counter electrojet events: First results, Geophys. Res. Lett., 34, L14101, doi:10.1029/2007GL030298.

Vineeth, C., T. Kumar Pant, and R. Sridharan (2009), Equatorial counter electrojets and polar stratospheric sudden warmings: A classical example of high latitude-low latitude coupling, Ann. Geophys., 27, 3147-3153, doi:10.5194/angeo-27-3147-2009.

Yamazaki, Y., A. D. Richmond, and K. Yumoto (2012a), Stratospheric warmings and the geomagnetic lunar tide: 1958-2007, J. Geophys. Res., 117, A04301, doi:10.1029/2012JA017514.

Yamazaki, Y., K. Yumoto, D. McNamara, T. Hirooka, T. Uozumi, K. Kitamura, S. Abe, and A. Ikeda (2012b), lonospheric current system during sudden stratospheric warming events, J. Geophys. Res., 117, A03334, doi:10.1029/2011JA017453.

Yamazaki, Y., A. D. Richmond, H. L. Liu, K. Yumoto, and Y. Tanaka (2012c), Sq current system during stratospheric sudden warming events in 2006 and 2009, J. Geophys. Res., 117, A12313, doi:10.1029/2012JA018116. 